\title{
Identification of Candidate Genes for Mayer-Rokitansky-Küster-Hauser Syndrome Using Genomic Approaches
}

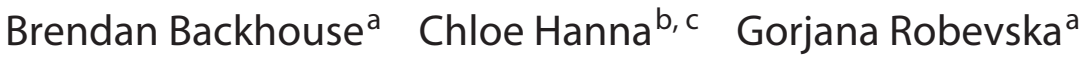 \\ Jocelyn van den Bergen ${ }^{a}$ Emanuele Pelosi ${ }^{\mathrm{e}}$ Cas Simons ${ }^{\mathrm{b}}$ Peter Koopman ${ }^{\mathrm{e}}$ \\ A. Zulfa Juniarto ${ }^{f}$ Sonia Grover ${ }^{a-c}$ Sultana Faradz ${ }^{f}$ Andrew Sinclair ${ }^{a, b}, d$ \\ Katie Ayers ${ }^{a, b}$ Tiong Y. Tan ${ }^{a-d}$ \\ ${ }^{a}$ Department of Paediatrics, University of Melbourne, ${ }^{b}$ Murdoch Children's Research Institute, 'Royal Children's \\ Hospital, 'Victorian Clinical Genetics Services, Melbourne, VIC, and eInstitute for Molecular Bioscience, \\ The University of Queensland, Brisbane, QLD, Australia; ${ }^{f}$ Center for Biomedical Research, Faculty of Medicine, \\ Diponegoro University (FMDU), Semarang, Indonesia
}

\section{Keywords}

Genotype · MURCS · Phenotype - Whole exome sequencing

\begin{abstract}
Mayer-Rokitansky-Küster-Hauser (MRKH) syndrome is a disorder of sex development which affects 1 in 4,500 females and is characterized by agenesis of müllerian structures, including the uterus, cervix, and upper vagina. It can occur in isolation (type 1) or in conjunction with various anomalies (type 2), with a subset of these comprising müllerian, renal, and cervicothoracic abnormalities (MURCS) association. The genetic causes of MRKH have been investigated previously yielding limited results, with massive parallel sequencing becoming increasingly utilized. We sought to identify genetic contributions to MRKH using a combination of microarray and whole exome sequencing (WES) on a cohort of 8 unrelated women with MRKH and MURCS. WES data were analysed using a candidate gene approach to identify potential
\end{abstract}

\section{KARGER}

(C) 2018 S. Karger AG, Basel

E-Mail karger@karger.com

www.karger.com/sxd contributing variants. Microarray analysis identified a 0.6-Mb deletion in the previously implicated $16 p 11.2$ region in a patient with MRKH type 2 . WES revealed 16 rare nonsynonymous variants in MRKH candidate genes across the cohort. These included variants in several genes, such as $\angle R P 10$ and DOCK4, associated with disorders with müllerian anomalies. Further functional studies of these variants will help to delineate their biological significance and expand the genotypic spectrum of MRKH.

(c) 2018 S. Karger AG, Basel

Mayer-Rokitansky-Küster-Hauser (MRKH) syndrome (OMIM 277000) is a congenital disorder of sex development (DSD). It affects the female reproductive tract of approximately 1 in 4,500 females and is charac-

K.A. and T.Y.T contributed equally to this work.

Tiong Yang Tan

Murdoch Children's Research Institute

Royal Children's Hospital

Flemington Road, Parkville, Melbourne, VIC 3052 (Australia)

E-Mail tiong.tan@vcgs.org.au 
terised by an aplastic or hypoplastic vagina, cervix, and uterus [Bombard and Mousa, 2014]. In addition to the core MRKH phenotype, a variety of associated anomalies, particularly renal and skeletal, are identified in approximately half of the affected females. Those with anomalies concerning the female reproductive tract only have MRKH type 1 and those with additional anomalies are designated as MRKH type 2, with a subset of these patients comprising müllerian, renal, and cervicothoracic abnormalities (MURCS) association (OMIM 601076). The congenital nature and familial clustering of this syndrome raises the possibility of a genetic aetiology [Christopoulos et al., 2009]. Monogenic causes of MRKH include WNT4, LHX1, and HNF1B and a gene that has been identified to cause other uterine malformations including uterus didelphys (HOXA10) [Lindner et al., 1999; Bingham et al., 2002; Biason-Lauber et al., 2004; Kobayashi et al., 2004; Cheng et al., 2011; Philibert et al., 2011; Ledig et al., 2012; Ekici et al., 2013]. Other genes have been proposed as candidates, either via their effects on müllerian development in animal models (i.e., Amh, Amhr2, Ctnnb1, Dach1, Dach2, Emx2, Hoxa11, Hoxa13, Lamc1, Pbx1, Rara, Rarb, Rarc, Wnt5a, Wnt7a, and Wt1) or their occurrence in human cases without functional validation (i.e., HNRNPCL1, ITIH5, LRP10, MMRP14, OR2T2, OR4M2, PAX8, PDE11A, RBM8A, SHOX, TBX6, WNT9B, and ZNF816) (online suppl. Table 1; for all online suppl. material, see www.karger.com/doi/10.1159/000494896). Additionally, multiple malformation syndromes reported with müllerian anomalies, such as Cornelia de Lange syndrome (OMIM 122470), provide some insight into genes or developmental pathways that play a role in the pathogenesis of MRKH (online suppl. Table 2).

Causative genetic factors have been identified in only a minority of individuals with MRKH. Most studies have employed microarrays or small gene panels/Sanger sequencing to investigate the causes of MRKH [Ledig et al., 2011; Ma et al., 2015; McGowan et al., 2015; Murry et al., 2015; Brucker et al., 2017; Williams et al., 2017; Ledig et al., 2018]. The development of massively parallel sequencing, including whole exome sequencing (WES), has broadened the scope for a more comprehensive genomic approach to identify genetic contributors to MRKH. To date, only a single study has adopted this approach in a cohort of 7 individuals with MRKH type 1 [Chen et al., 2015].

The objective of this study was to use WES and chromosomal microarray to characterize the genomic variation in a retrospective cohort of individuals with MRKH and MURCS.

Candidate Genes for Mayer-Rokitansky-

Küster-Hauser Syndrome

\section{Materials and Methods}

\section{Participants}

Inclusion criteria for recruitment to this study were MRKH type 1 or 2 or MURCS diagnosed clinically or radiographically. We excluded individuals with a müllerian abnormality other than uterovaginal agenesis unless they met the criteria for MURCS association. Using the databases of The Royal Children's Hospital $(\mathrm{RCH})$ and Victorian Clinical Genetics Services (VCGS), we identified potential participants who were contacted by their primary clinician. We also recruited participants from Indonesia under an existing collaboration with the Center for Biomedical Research (Cebior) FMDU. Each participant was assigned a number (e.g., MRKH1, MRKH2, MURCS1, etc.) for de-identification purposes.

\section{Phenotyping}

All clinical details were collected retrospectively from medical records of RCH and VCGS or the DSD team Cebior FMDU. Data were recorded in a Microsoft Excel spreadsheet and Phenotips using Human Phenotype Ontology terms [Girdea et al., 2013]. Müllerian anomalies were often identified by multiple modalities, including ultrasound, MRI, and laparoscopy, sometimes producing conflicting clinical reports. Where this was the case, the phenotype we chose to record was preferentially that described by laparoscopy, then MRI, and finally ultrasound.

\section{Genetic Analysis}

DNA was extracted from peripheral EDTA blood by the VCGS Molecular Genetics laboratory or local laboratories using standard protocols. DNA quality was assessed by a TapeStation 2200 (Agilent) and concentration was measured using Qubit dsDNA Broad Range (Thermofisher). Cytogenetics confirmed that all patients had a 46,XX karyotype. Extracted DNA samples were sent for microarray and WES.

\section{Microarray}

All samples were first analysed for copy number variants (CNVs) by SNP microarray undertaken by the VCGS cytogenetics laboratory. Three participants (MRKH5, MURCS1, and MURCS2) had previously undergone clinical microarray testing using the HumanCytoSNP-12 v2.1 (Illumina) technology; however, given the poor coverage of $\mathrm{MRKH}$-specific regions by this test, all participants were subsequently reanalysed using the Omni 2.5-8 (Illumina) technology. This platform provides high-level SNP coverage of exonic regions (1-2 SNP probes per $10 \mathrm{~kb}$ ) through the entire genome. The assay will detect copy number changes to an average resolution of 10-20 kb, long continuous stretches of homozygosity (LCSH) regions $>2 \mathrm{Mb}$, and mosaicism between 10 $20 \%$. Library preparation and sequencing was carried out according to the manufacturer's instructions.

\section{Whole Exome Sequencing}

WES was undertaken by the VCGS Translational Genomics Unit using the Agilent SureSelect QXT (transposase-based fragmentation) Clinical Research Exome (CRE) technology with 100× coverage on a HiSeq2500. Library preparation, sequencing, and analysis were carried out as per the manufacturer's instructions.

Variants were characterised using the Melbourne Genomics Health Alliance shared bioinformatics pipeline, Cpipe [Sadedin et al., 2015] version 0.9.8 (http://cpipeline.org). An internal database

Sex Dev 2019;13:26-34

DOI: $10.1159 / 000494896$ 
was used to filter technical and locally recurrent variants against participant data.

Nonsynonymous, splice site, and nonsense variants, and small insertions and deletions present at a frequency of $<0.1 \%$ in the 1000 Genomes Project (http://1000genomes.org) and ExAC (http://exac.broadinstitute.org/) repositories were assessed further. Variants in genes previously identified to be diagnostic or candidates for MRKH or diagnostic for other syndromes with müllerian involvement, as summarised in online suppl. Tables 1 and 2, respectively, were reportable. Variant population frequency data was accessed from both ExAC and gnomAD, using both the total frequency and specific allele frequencies for geographic regions when the origin of the patient was known. The predicted effect on gene function was calculated by the in silico software programs SIFT (http://sift.bii.a-star.edu.sg/), Polyphen2 (http://genetics.bwh.harvard.edu/pph2/), as well as CADD raw scores [Kircher et al., 2014] and GERP++ scores [Davydov et al., 2010]. A gene-associated phenotype was also assessed by human cases reported in OMIM (http://www.omim.org/), mouse models in the Mouse Genome Informatics database (http://www.informatics. jax.org/), and the known role in physiological processes.

\section{Results}

\section{Participants}

Of the initial cohort of 26 potentially eligible participants, 8 women aged between 24 and 35 years (median age 30.5 years) were recruited and consented (Table 1 ). Of the 18 individuals who were not included, 1 declined to participate, 11 did not return the consent forms, 2 provided consent but did not provide a DNA sample, and 4 individuals were excluded because there were insufficient clinical notes to determine an accurate phenotypic category. There was no reported parental consanguinity or family history of müllerian abnormalities. Four individuals were classified as MRKH type 1 (MRKH1-4), and had presented to the clinic with primary amenorrhea or difficulty with intercourse. Two patients were classified as MRKH type 2 (MRKH5 and 6), and 2 had a diagnosis of MURCS association (MURCS1 and 2) (Table 1). Individual MURCS2 has been previously reported by Tan et al. [2007]. Associated anomalies in patients with MRKH type 2 and MURCS included those affecting the urogenital, musculoskeletal, gastrointestinal, cardiovascular, and neurological systems (Table 1 ).

\section{Copy Number Variants Detected by SNP Microarray}

A known, recurrent deletion of approximately $0.6 \mathrm{Mb}$ was detected on chromosome $16 \mathrm{p} 11.2$ (location 29,595,483-30,199,713) in one participant with MRKH type 2 (MRKH6) and affected the candidate gene TBX6. All other participants had normal SNP microarrays.

\section{Whole Exome Sequencing}

The total number of variants identified by WES in each participant ranged from 50,187 to 51,416 with a median of 50,532 , but after bioinformatic filtering, there were 356-771 (median 559) variants per participant considered for further assessment. We screened for rare $(<0.1 \%)$ nonsynonymous or splice site variants in diagnostic and candidate genes (online suppl. Tables 1, 2). These are reported in Table 2 . In total, we identified 16 variants in 6 participants (MRKH2, MRKH3, MRKH4, MRKH5, MRKH6, and MURCS1) that were considered potentially contributory to their clinical MRKH phenotype (Table 2 ).

No variants in candidate genes or CNVs were identified in MRKH1. While no CNVs were detected in MRKH2, she did carry rare variants in several MRKH candidate genes. A heterozygous LRP10 variant (c.1255G>A, p.Asp419Asn) is both rare (ExAC frequency of 0.000033 , gnomAD $=0.00002032$ ) and predicted to be damaging (Table 2). This gene has been implicated in a previously reported individual with MRKH [Rall et al., 2015], and this variant affects a conserved residue in the third LDL receptor domain. Other aberrations identified in participant MRKH2 were a heterozygous variant in FRAS1 (c.1165G>A, p.Val389Ile), which was novel and predicted to be damaging (Table 2), and variants in both ESCO2 and CEP290, which were novel but predicted to be benign/tolerated (Table 2). Both of these genes are involved in syndromes with müllerian involvement [Fraser syndrome (OMIM 219000) and Roberts syndrome (OMIM 268300)]. Finally, variants in this participant were also found in CC2D2A and KIF14, responsible for COACH syndrome (OMIM 216360) and Meckel syndrome 12 (OMIM 616258), respectively ( $\mathrm{Ta}$ ble 2).

Patient MRKH3 had a heterozygous RSPO4 variant, p.Arg211Trp, which has a maximum allele frequency in ExAC of 0.0001129 , and was predicted to be damaging.

Patient MRKH4 had a rare and damaging variant in NPHP3 (Table 2), (c.3353G>A, p.Arg1118His) (ExAC frequency of 0.000017), which is involved in an autosomal recessive syndrome with müllerian involvement [Meckel-Gruber syndrome (OMIM 267010)]. Similarly, a heterozygous variant in DYNC2H1 (c.584C>T, p.Ala195Val) (ExAC frequency of 0.0002351 and predicted to be damaging) was detected. Bi-allelic mutations in this gene cause short-rib thoracic dysplasia (OMIM 613091).

Several variants in candidate genes were identified in MRKH5; a novel heterozygous variant was found in
28

Sex Dev 2019;13:26-34

DOI: $10.1159 / 000494896$
Backhouse et al. 
Table 1. Clinical phenotypes of individuals recruited to this study

\begin{tabular}{|c|c|c|c|c|c|c|}
\hline Participant & Urogenital & Musculoskeletal & $\begin{array}{l}\text { Gastro- } \\
\text { intestinal }\end{array}$ & $\begin{array}{l}\text { Cardio- } \\
\text { vascular }\end{array}$ & Neurological & Other \\
\hline $\begin{array}{l}\text { MRKH1 } \\
\text { (type 1) }\end{array}$ & $\begin{array}{l}\text { Uterovaginal agenesis, } \\
\text { presented with primary } \\
\text { amenorrhea and blind } \\
\text { ending vagina, fusion of } \\
\text { the labia minora }\end{array}$ & - & - & - & - & - \\
\hline $\begin{array}{l}\text { MRKH2 } \\
\text { (type 1) }\end{array}$ & $\begin{array}{l}\text { Uterovaginal agenesis, } \\
\text { primary amenorrhea, } \\
\text { rudimentary left ovary, } \\
\text { polycystic right ovary }\end{array}$ & - & - & - & - & - \\
\hline $\begin{array}{l}\text { MRKH3 } \\
\text { (type 1) }\end{array}$ & $\begin{array}{l}\text { Uterovaginal agenesis, } \\
\text { presented with primary } \\
\text { amenorrhea }\end{array}$ & - & - & - & - & - \\
\hline $\begin{array}{l}\text { MRKH4 } \\
\text { (type 1) }\end{array}$ & $\begin{array}{l}\text { Uterovaginal agenesis, } \\
\text { presented with primary } \\
\text { amenorrhea }\end{array}$ & - & - & - & - & - \\
\hline $\begin{array}{l}\text { MRKH5 } \\
\text { (type 2) }\end{array}$ & Uterovaginal agenesis & $\begin{array}{l}\text { Bilateral absent radii, } \\
\text { absent right thumb, } \\
\text { hypoplastic left thumb }\end{array}$ & - & $\begin{array}{l}\text { Atrial septal } \\
\text { defect }\end{array}$ & - & $\begin{array}{l}\text { Inguinal hernia } \\
\text { in infancy }\end{array}$ \\
\hline $\begin{array}{l}\text { MRKH6 } \\
\text { (type 2) }\end{array}$ & $\begin{array}{l}\text { Uterovaginal agenesis, } \\
\text { absent fallopian tubes, } \\
\text { right ovarian agenesis, } \\
\text { ectopic left ovary, bilateral } \\
\text { unduplicated ectopic } \\
\text { ureters, hypoplastic } \\
\text { bladder }\end{array}$ & - & - & - & - & $\begin{array}{l}\text { Type } 1 \text { von } \\
\text { Willebrand } \\
\text { disease, } \\
\text { inguinal hernia } \\
\text { in infancy }\end{array}$ \\
\hline MURCS1 & $\begin{array}{l}\text { Right unicornuate uterus, } \\
\text { vaginal agenesis, } \\
\text { hydronephrosis }\end{array}$ & $\begin{array}{l}\text { Fused vertebrae (C2-3, } \\
\text { C6-7, L3-4), butterfly } \\
\text { vertebra (L3), lumbar } \\
\text { scoliosis, dislocated radial } \\
\text { head bilaterally }\end{array}$ & $\begin{array}{l}\text { Imperforate } \\
\text { anus }\end{array}$ & $\begin{array}{l}\text { Atrial septal } \\
\text { defect }\end{array}$ & - & $\begin{array}{l}\text { Dysmorphic } \\
\text { features }\end{array}$ \\
\hline MURCS2 & $\begin{array}{l}\text { Uterovaginal agenesis, } \\
\text { right ovarian agenesis, left } \\
\text { multi-cystic kidney, right } \\
\text { pelvicoureteric junction } \\
\text { obstruction, neurogenic } \\
\text { bladder }\end{array}$ & $\begin{array}{l}\text { Fused vertebrae (C4-5), } \\
11 \text { pairs of ribs, thoracic } \\
\text { kyphoscoliosis, chest wall } \\
\text { asymmetry, bilateral wrist } \\
\text { flexion, radial deviation of } \\
\text { tapering fingers, fifth } \\
\text { finger clinodactyly, } \\
\text { bilateral camptodactyly of } \\
\text { fingers and second } \\
\text { and third toes, torticollis }\end{array}$ & - & - & $\begin{array}{l}\text { Cortical } \\
\text { heterotopia, } \\
\text { periventricular } \\
\text { leukomalacia, } \\
\text { seizures, } \\
\text { intellectual } \\
\text { disability } \\
\text { (IQ 55) }\end{array}$ & $\begin{array}{l}\text { Dysmorphic } \\
\text { features, } \\
\text { subclinical } \\
\text { cataracts }\end{array}$ \\
\hline
\end{tabular}

$B M P R 1 B$ (c.70A $>$ C, p.Thr24Pro) (predicted to be benign/tolerated) and a rare heterozygous variant in MKKS (c.67A $>$ G, p.Arg23Gly) (ExAC frequency of 0.00054 ). Both genes are involved in syndromes with müllerian involvement [acromesomelic dysplasia (OMIM 609441) and McKusick-Kaufman syndrome
(OMIM 236700)]. A variant in the DOCK4 gene was also found (Table 2).

Patient MRKH6 carried a variant in MKKS (ExAC = 0.005557), which was predicted to be damaging, and another variant in VWF probably causative for her unrelated genetic condition. This variant (c.7390C $>\mathrm{T}$,
Candidate Genes for Mayer-Rokitansky-

Küster-Hauser Syndrome 


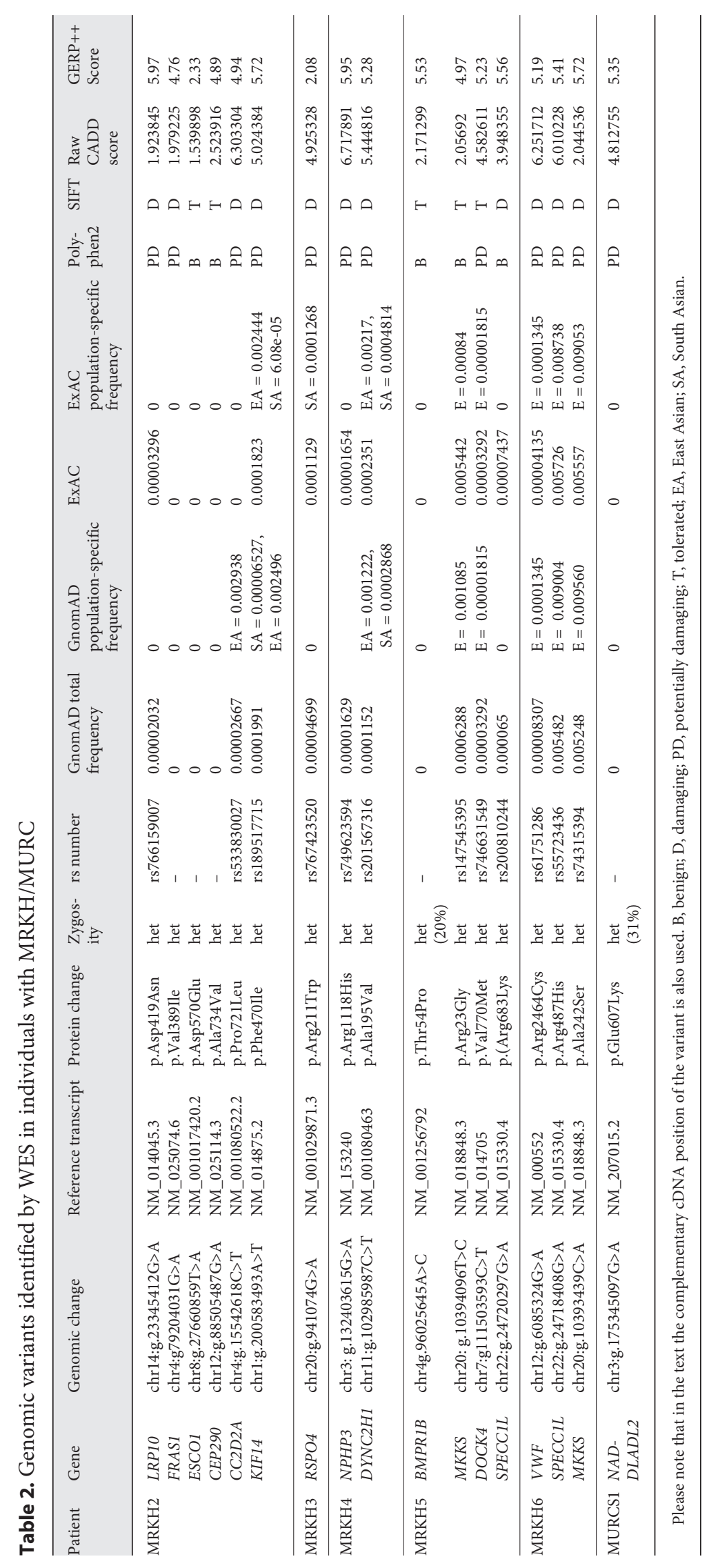


p.Arg2464Cys) (ExAC frequency of 0.000041) has previously been confirmed diagnostic for von Willebrand disease (OMIM 193400) [Lester et al., 2007].

A heterozygous variant in the NAALADL2 gene was found in individual MURCS1. The variant was novel and predicted to be damaging (Table 2), however, it was only identified in around $30 \%$ of reads suggesting it may be mosaic.

\section{Discussion}

The phenotypes observed in this small cohort of participants with MRKH and MURCS represent the previously reported diverse spectrum involving the urogenital, musculoskeletal, cardiovascular, and neurological systems [Rall et al., 2015]. We did not identify a consistent pattern of recurrent anomalies, but the most frequently associated malformations included abnormalities of the forearms and spine and atrial septal defect. Microarray identified a chromosomal CNV in 1 of the $8(12.5 \%)$ participants, which is a frequency similar to previous reports [Nik-Zainal et al., 2011]. The deletion of chromosome $16 \mathrm{p} 11.2$ was identified in individual MRKH6 with MRKH type 2 . In addition to the typical müllerian anomalies of MRKH, she had bilateral inguinal hernias repaired in infancy and von Willebrand disease. Recurrent deletions of this region have previously been reported in both MRKH type 1 and 2 as well as in MURCS [Nik-Zainal et al., 2011] and are reported to contribute to around 1\% of MRKH patients [Morcel et al., 2012]. In addition to this, splice site variants of TBX6, a gene within this region, have been identified in individuals with MRKH [Nik-Zainal et al., 2011; Sandbacka et al., 2013]. Individual MRKH6 also has a VWF variant (c.7390C > T, p.Arg2464Cys), which has previously been reported in a patient with von Willebrand disease with functional validation [Lester et al., 2007]. This variant was able to provide a genetic diagnosis for this aspect of the participant's phenotype, and in combination with the 16p11.2 deletion identified by microarray, a comprehensive genetic diagnosis was achieved.

WES identified 16 variants in 14 genes that may represent candidates for both MRKH type 1 and 2, and 1 unrelated variant in the $V W F$ gene.

In MRKH2, the most convincing variant was in LRP10. This gene has been suggested as a candidate for MRKH due to the finding of a chromosomal duplication of $14 \mathrm{q} 11.2$ limited to the rudimentary uterine tissue of an affected individual who was phenotypically discordant from her monozygotic twin [Rall et al., 2015]. Fur-

Candidate Genes for Mayer-Rokitansky-

Küster-Hauser Syndrome thermore, $L R P 10$ has been shown to be a negative regulator of the canonical $\mathrm{Wnt} / \beta$-catenin pathway [Jeong et al., 2010], a key signalling pathway for müllerian development. Our finding of the variant c.1255G $>$ A, p.Asp419Asn in participant MRKH2 was considered to be potentially contributory; however, there have been no functional studies to elucidate direct effects of loss or gain of function in müllerian tissues.

Several other rare variants were identified in participant MRKH2, i.e., FRAS1 (c.1165G>A, p.Val389Ile), ESCO2 (c.1710T>A, p.Asp570Glu), and CEP290 (c.2201C > T, p.Ala734Val). Bi-allelic mutations in these genes cause multisystemic syndromes: FRAS1 is implicated in Fraser syndrome, characterised by cryptophthalmos and syndactyly, ESCO2 is implicated in Roberts syndrome, characterised by long bone deficiencies and cleft lip and palate, and CEP290 can cause several syndromes with a variety of associated phenotypes. Whilst müllerian anomalies are occasionally observed in these conditions, it is unlikely that these variants in heterozygous form are causative of the MRKH type 1 phenotype in this individual. Whether these variants exert a combinatorial effect resulting in the müllerian anomalies in MRKH2 is speculative and would require further study. Finally, variants were also found in CC2D2A and KIF14, responsible for COACH syndrome and Meckel syndrome 12, respectively. However, given that these conditions are autosomal recessive and these variants had allele frequencies of up to $0.2 \%$ in some Asian populations, they are unlikely to be causative.

MRKH3 had just 1 variant in the candidate gene RSPO4. A patient with Herlyn-Werner-Wunderlich syndrome and a partial duplication of RSPO4 [Ledig et al., 2018] has been described previously, although homozygous mutations of RSPO4 are associated with congenital anonychia (OMIM 206800), suggesting that heterozygous missense mutations in this gene may be tolerated or have a different mechanism of action to that previously reported.

Heterozygous variants were identified in NPHP3 (c.3353G>A, p.Arg1118His) and DYNC2H1 (c.584C>T, p.Ala195Val) in participant MRKH4. Bi-allelic mutations in both genes cause disorders in which müllerian abnormalities have been reported: Meckel-Gruber syndrome, caused by mutations in NPHP3, consists of the classic triad of cystic renal disease, a central nervous system malformation, and polydactyly [Bergmann et al., 2008], and short-rib thoracic dysplasia, caused by bi-allelic mutations in DYNC2H1 [Merrill et al., 2009]. We reasoned that these variants in isolation were unlikely to be causative of the müllerian anomalies in MRKH4.

Sex Dev 2019;13:26-34 DOI: $10.1159 / 000494896$ 
Four variants were identified in participant MRKH5, a woman with MRKH type 2, a novel heterozygous variant found in BMPR1B (c.70A >C, p.Thr24Pro) and a rare heterozygous variant in $M K K S$ (c.67A $>\mathrm{G}, \mathrm{p}$.Arg23Gly). Variants in BMPR1B are known to cause acromesomelic dysplasia, where one patient was also reported to have müllerian anomalies [Demirhan et al., 2005]. The previously reported homozygous 8-bp deletion resulted in an absent fibula, brachydactyly, ulnar deviation of the hands, fusion of the carpal and tarsal bones, ovarian dysfunction, and a hypoplastic uterus. Individual MRKH5 had upper limb abnormalities, including aplastic/hypoplastic thumbs, and absent radii. However, these are clinically distinct to acromesomelic dysplasia, and the heterozygous $B M P R 1 B$ variant is unlikely to be causative of the $\mathrm{MRKH}$ in this individual. Haploinsufficiency of $B M P R 1 B$ can cause a form of brachydactyly (OMIM 616849), although this is a distinct phenotype discordant from that observed in participant MRKH5, and functional validation of this variant would be required to draw this correlation. The second heterozygous variant in MRKH5 in the gene responsible for causing McKusick-Kaufman syndrome was considered due to the imperforate vagina seen in this syndrome; however patients usually present with polydactyly, in contrast to our patient [McKusick et al., 1964]. In addition to this, McKusick-Kaufman syndrome, again, shows an autosomal recessive inheritance pattern which does not support our findings. Finally, this patient also had a single nucleotide variant in the DOCK4 candidate gene. This is the second report of a patient carrying an aberration in this gene, the first was a patient with partial septate uterus who carried a 218 -kb gain partly affecting DOCK4 [Ledig et al., 2018]. DOCK4 is a guanine nucleotide exchange factor (GEF), involved in the regulation of adherens junctions between cells and thought to play a role in cell migration. Further functional analysis is now required to assess any potential role for this gene in müllerian duct development and disease.

Like patient 5, MRKH6 had variants in MKKS and SPECC1L. Heterozygous missense variants in SPECC1L have been implicated in oblique facial clefting and Opitz G/BBB syndrome (OMIM145410). In the later, where a missense variant was found to segregate with the disease within a family, one of the affected individuals was found to have a bicornate uterus [Kruszka et al., 2015]. Interestingly, the 2 variants we found fall within the third coil-coil domain of SPECC1L, whereas previously implicated variants in Opitz G/BBB syndrome and facial clefting fall within the second coil-coil domain or within the Calponin-homology domain. Further investigation into the functional relevance of these candidate $\mathrm{MRKH}$-associated variants is warranted.

Individual MURCS1 was found to have a variant in NAALADL2, previously proposed as a candidate gene for Cornelia de Lange syndrome due to a patient with a de novo balanced translocation with a breakpoint at chromosome 3q26.3 involving NAALADL2 [Tonkin et al., 2004]. Recently, another report has found 2 patients with either partial septate uterus or uterus didelphys, with small duplications within this gene [Ledig et al., 2018]. Our patient had right unicornuate uterus, vaginal agenesis and hydronephrosis in addition to fused vertebrae (C2-3, C6-7, L3-4), butterfly vertebra (L3), lumbar scoliosis, dislocated radial head bilaterally, imperforate anus, and an atrial septal defect.

No variants in individual MURCS2 were deemed causative after curation. Given the clinical heterogeneity and complexity of the MRKH spectrum, in particular MURCS, the low number of participants in this study was a major limitation to fully realising the potential of genomic approaches to this clinical entity. With a larger cohort, there would be a greater ability to identify non-Mendelian patterns of inheritance, a likely scenario in many cases of MRKH and MURCS.

In summary, the phenotypic diversity identified within our population further highlights the clinical heterogeneity of MRKH. The use of limited genetic analysis techniques such as microarray and small gene panels are therefore unable to capture a large portion of diagnostic or candidate genes responsible for the syndrome. WES, however, was able to identify a greater yield of variants that might underlie MRKH, resulting in further validation of previously reported candidate genes DOCK4, LRP10, and NAALADL2. However further functional studies are required to confirm their significance. In addition to this, by using WES in combination with microarray, we were able to dissect the cause of complex phenotypes in individual MRKH6, with MRKH type 2 in addition to an unrelated genetic disorder, von Willebrand disease.

Drawing genotypic-phenotypic correlations such as those identified in this study may expand the MRKHMURCS genotypic-phenotypic spectrum in addition to the spectrum of phenotypes caused by variants in previously known genes. Furthermore, this work forms the basis for future functional studies (including mouse mutants), which will test the contribution of these candidate genes to müllerian duct development and disease. Previous studies on MRKH patients using low resolution microarrays or gene panels alone identified very few potentially causative gene variants. By contrast, we have shown
32

Sex Dev 2019;13:26-34 DOI: $10.1159 / 000494896$
Backhouse et al. 
that the combined use of high-resolution microarray and WES was able to identify potential candidate gene variants in the majority of our MRKH participants.

\section{Acknowledgement}

We would like to thank the women of this study for their participation and the Translational Genomics Unit at the Murdoch Children's Research Institute for their assistance. We are also grateful to the DSD team of FMDU/Dr. Kariadi Hospital.

\section{Statement of Ethics}

All participants provided written informed consent as part of The Royal Children's Hospital Ethics committee approved study (HREC22073) or their local institution, the medical ethics committee of FMDU/Dr. Kariadi Hospital, Semarang.

\section{Disclosure Statement}

The authors have no conflicts of interest to declare.

\section{References}

-Bergmann C, Fliegauf M, Brüchle NO, Frank V, Olbrich H, et al: Loss of nephrocystin-3 function can cause embryonic lethality, MeckelGruber-like syndrome, situs inversus, and renal-hepatic-pancreatic dysplasia. Am J Hum Genet 82:959-970 (2008).

-Biason-Lauber A, Konrad D, Navratil F, Schoenle EJ: A WNT4 mutation associated with Müllerian-duct regression and virilization in a 46,XX woman. N Engl J Med 351:792-798 (2004).

Bingham C, Ellard S, Cole TRP, Jones KE, Allen LIS, et al: Solitary functioning kidney and diverse genital tract malformations associated with hepatocyte nuclear factor-1beta mutations. Kidney Int 61:1243-1251 (2002).

- Bombard DS, Mousa SA: Mayer-RokitanskyKuster-Hauser syndrome: complications, diagnosis and possible treatment options: a review. Gynecol Endocrinol 30:618-623 (2014).

Brucker SY, Frank L, Eisenbeis S, Henes M, Wallwiener D, et al: Sequence variants in ESR1 and OXTR are associated with Mayer-Rokitansky-Küster-Hauser syndrome. Acta Obstet Gynecol Scand 96:1338-1346 (2017).

Chen M-J, Wei S-Y, Yang W-S, Wu T-T, Li H-Y, et al: Concurrent exome-targeted next-generation sequencing and single nucleotide polymorphism array to identify the causative genetic aberrations of isolated Mayer-Rokitansky-Küster-Hauser syndrome. Hum Reprod 30:1732-1742 (2015).

Cheng Z, Zhu Y, Su D, Wang J, Cheng L, et al: A novel mutation of HOXA10 in a Chinese woman with a Mullerian duct anomaly. Hum Reprod 26:3197-3201 (2011).

-Christopoulos P, Gazouli M, Fotopoulou G, Creatsas $\mathrm{G}$ : The role of genes in the development of Mullerian anomalies: where are we today? Obstet Gynecol Surv 64:760-768 (2009).

-Davydov EV, Goode DL, Sirota M, Cooper GM, Sidow A, Batzoglou S: Identifying a high fraction of the human genome to be under selective constraint using GERP++. PLoS Comput Biol 6:e1001025 (2010).
Demirhan O, Türkmen S, Schwabe GC, Soyupak $\mathrm{S}$, Akgül E, et al: A homozygous BMPR1B mutation causes a new subtype of acromesomelic chondrodysplasia with genital anomalies. J Med Genet 42:314-317 (2005).

Ekici AB, Strissel PL, Oppelt PG, Renner SP, Brucker S, et al: HOXA10 and HOXA13 sequence variations in human female genital malformations including congenital absence of the uterus and vagina. Gene 518:267-272 (2013).

Girdea M, Dumitriu S, Fiume M, Bowdin S, Boycott KM, et al: PhenoTips: patient phenotyping software for clinical and research use. Hum Mutat 34:1057-1065 (2013).

> Jeong Y-H, Sekiya M, Hirata M, Ye M, Yamagishi A, et al: The low-density lipoprotein receptorrelated protein 10 is a negative regulator of the canonical Wnt/beta-catenin signaling pathway. Biochem Biophys Res Commun 392: 495-499 (2010).

Kircher M, Witten DM, Jain P, O'Roak BJ, Cooper GM, Shendure J: A general framework for estimating the relative pathogenicity of human genetic variants. Nat Genet 46:310-315 (2014).

Kobayashi A, Shawlot W, Kania A, Behringer RR: Requirement of Lim 1 for female reproductive tract development. Development 131:539549 (2004).

Kruszka P, Li D, Harr MH, Wilson NR, Swarr D, et al: Mutations in SPECC1L, encoding sperm antigen with calponin homology and coiledcoil domains 1-like, are found in some cases of autosomal dominant Opitz G/BBB syndrome. J Med Genet 52:104-110 (2015).

Ledig S, Schippert C, Strick R, Beckmann MW, Oppelt PG, Wieacker P: Recurrent aberrations identified by array-CGH in patients with Mayer-Rokitansky-Küster-Hauser syndrome. Fertil Steril 95:1589-1594 (2011). Ledig S, Brucker S, Barresi G, Schomburg J, Rall
K, Wieacker P: Frame shift mutation of LHX1 is associated with Mayer-Rokitansky-KusterHauser (MRKH) syndrome. Hum Reprod 27: 2872-2875 (2012).
Ledig S, Tewes A-C, Hucke J, Römer T, Kapczuk $\mathrm{K}$, et al: Array-CGH analysis in patients with Müllerian fusion anomalies. Clin Genet 93: 640-646 (2018).

Lester WA, Guilliatt AM, Enayat MS, Rose P, Hill FGH: The R2464C missense mutation in the von Willebrand factor gene causes a novel abnormality of multimer electrophoretic mobility and falls into the subgroup of type 2 von Willebrand disease 'unclassified'. Thromb Haemost 97:159-160 (2007).

Lindner TH, Njolstad PR, Horikawa Y, Bostad L, Bell GI, Sovik O: A novel syndrome of diabetes mellitus, renal dysfunction and genital malformation associated with a partial deletion of the pseudo-POU domain of hepatocyte nuclear factor-1beta. Hum Mol Genet 8: 2001-2008 (1999).

Ma W, Li Y, Wang M, Li H, Su T, et al: Associations of polymorphisms in WNT9B and PBX1 with Mayer-Rokitansky-Küster-Hauser syndrome in Chinese Han. PLoS One 10:e0130202 (2015).

- McGowan R, Tydeman G, Shapiro D, Craig T, Morrison N, et al: DNA copy number variations are important in the complex genetic architecture of müllerian disorders. Fertil Steril 103:1021-1030.e1 (2015).

McKusick VA, Bauer RL, Koop CE, Scott RB: Hydrometrocolpos as a simply inherited malformation. JAMA 189:813-816 (1964).

Merrill AE, Merriman B, Farrington-Rock C, Camacho N, Sebald ET, et al: Ciliary abnormalities due to defects in the retrograde transport protein DYNC2H1 in short-rib polydactyly syndrome. Am J Hum Genet 84:542-549 (2009).

Morcel K, Dallapiccola B, Pasquier L, Watrin T, Bernardini L, Guerrier D: Clinical utility gene card for: Mayer-Rokitansky-Küster-Hauser syndrome. Eur J Hum Genet 20:1-3 (2012).

Murry JB, Santos XM, Wang X, Wan Y-W, Van den Veyver IB, Dietrich JE: A genome-wide screen for copy number alterations in an adolescent pilot cohort with müllerian anomalies. Fertil Steril 103:487-493 (2015).
Candidate Genes for Mayer-RokitanskyKüster-Hauser Syndrome
Sex Dev 2019;13:26-34 DOI: $10.1159 / 000494896$ 
-Nik-Zainal S, Strick R, Storer M, Huang N, Rad R, et al: High incidence of recurrent copy number variants in patients with isolated and syndromic Müllerian aplasia. J Med Genet 48: 197-204 (2011).

- Philibert P, Biason-Lauber A, Gueorguieva I, Stuckens C, Pienkowski C, et al: Molecular analysis of WNT4 gene in four adolescent girls with mullerian duct abnormality and hyperandrogenism (atypical Mayer-Rokitansky-Küster-Hauser syndrome). Fertil Steril 95:2683-2686 (2011).
Rall K, Eisenbeis S, Barresi G, Rückner D, Walter $M$, et al: Mayer-Rokitansky-Küster-Hauser syndrome discordance in monozygotic twins: matrix metalloproteinase 14 , low-density lipoprotein receptor-related protein 10 , extracellular matrix, and neoangiogenesis genes identified as candidate genes in a tissue-specific mosaicism. Fertil Steril 103:494-502.e3 (2015).

- Sadedin SP, Dashnow H, James PA, Bahlo M, Bauer DC, et al: Cpipe: a shared variant detection pipeline designed for diagnostic settings. Genome Med 7:68 (2015).

-Sandbacka M, Laivuori H, Freitas É, Halttunen M, Jokimaa V, et al: TBX6, LHX1 and copy number variations in the complex genetics of Müllerian aplasia. Orphanet J Rare Dis 8:125 (2013).
Tan TY, Whitelaw C, Savarirayan R: A patient with Mullerian abnormalities, renal dysplasia, cervical spine fusion, cataracts and intellectual disability: MURCS-plus? Clin Dysmorphol 16:271-273 (2007).

Tonkin ET, Smith M, Eichhorn P, Jones S, Imamwerdi $\mathrm{B}$, et al: A giant novel gene undergoing extensive alternative splicing is severed by a Cornelia de Lange-associated translocation breakpoint at 3q26.3. Hum Genet 115:139_ 148 (2004).

Williams LS, Demir Eksi D, Shen Y, Lossie AC, Chorich LP, et al: Genetic analysis of MayerRokitansky-Kuster-Hauser syndrome in a large cohort of families. Fertil Steril 108:145151.e2 (2017). 